\title{
ASSESSMENT OF PROJECT MANAGEMENT TASKS REQUIREMENT ACCORDING TO PMBOK METHODOLOGY IN THE BAGHDAD GOVERNORATE
}

\author{
Mustafa Kais Kmal \\ Supervised by - Prof. Dr. Salah Aldin A. K. ALKubaisi
}

DOI: $10.37648 /$ ijrssh.v10i01.004

Received:06 ${ }^{\text {th }}$ September, 2019; Accepted:08th October, 2019; Published: $29^{\text {th }}$ October, 2019

\begin{abstract}
This study aims to assess the tasks statement for the different practices of project management according to the (PMBOK methodology) by using the requirements mentioned in the "project management experience knowledge-self assessment manual " issued by the Professional Institute of Project Management has been selected Baghdad governorate as a field to apply this study. the results are showed the presence of weakness in the performance of tasks subject of the study sample was classified as less than the required level, and finally a number of recommendations, the most important of the need to set up training courses and spraying work within the field of Project management to define how to handle and perform various tasks to manage projects efficiently and effectively, which will contribute significantly to the success of the projects.
\end{abstract}

\section{INTRODUCTION}

Due to the decline in the success of the service sector of government projects rates, especially nature-oriented service that has a direct impact on the citizen (client) so it was necessary to work professionally for the maturity of these practices and stand on the actual reality of the extent of implementation and to achieve the factors that directly or indirectly contribute to the the possibility of switching to the adoption of philosophy within the public sector, which will be reflected positively on the success of the projects because of the property this way high precision towards achieving the goals, regardless of big business or small size.

\section{RESEARCH METHODOLOGY}

a- Problem of study

Lack of a clear vision and the absence of the basic requirements to be followed in accordance with the specific methodology for the purpose of reaching the aim of the study was formulated problem asking is there to know how the tasks and duties apply to all activities related to the field of project management runs smoothly and high professional.

b- Importance of studying

It derives research significance from being dealt with recently a key theme, as is a project management approach may confer excellence in the performance of organizations and can framing the importance of the first research 
with double my view is the intellectual contribution either in the practical side will assess the areas of Tasks and functions for project management and stand on the actual reality of project management as this study provides an integrated data and describes tasks phrases for each group of project management groups, which include (start racing, planning, implementation, monitoring and control, closing)

\section{c- Objectives of the study:}

Examine the reality of the performance of the various activities of the practices of project management in the service sector and evaluation and in particular in (Baghdad governorate) as well as determine the application of modern methodologies for project management and knowledge of the barriers to their application and try to make recommendations for improvement and maturity to enhance the success of the projects in the service sectors and the extent to benefit from previous lessons and experiences of companies that have the expertise and reputation of great in the field of project management requirements.

\section{d- Research Sample and community:}

The community of study included the service sector projects management in Iraq, Baghdad governorate was chosen as a sample of study because the diversity of its projects

\section{e- Methods, tools and measures:}

The case study method and descriptive style analytical were used in writing of study as well as information and results obtained from Baghdad governorate which handles the subject of study.

\section{LITERATURE REVIEW}

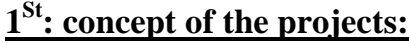

The study (Söderlung ,2004,185) define project is an organizational unit dedicated to achieving a particular goal or overall success in the complete product development on time, within budget and in compliance with the performance specifications defined in advance. (Burke, 2009:2) and (Turner, 2009:2), and (S Choudhury, 2009:1) went to the same-direction, they already knew the project that he endeavor to organize the human resources, financial and material resources in a new way to do the scope of the unique work and in the limits of cost and time in order to achieve beneficial change defined by quantitative and qualitative targets. (Maylor, 2010:5) was mentioned in a book entitled Project Management in its fourth edition The project is the process of creating a building on a specific task, which was completed at a given time or within the agreed time frame under the constraints including resources and external conditions value.As different (Path, 2011: 2) in the project definition as described as a temporary organization, which is created through the routine, which consists of members is unlikely to work together again. While (Nwagbogwu, 2011: 23) compatible with (Gido \& Clements, 2006) in the project is defined as an effort to achieve a particular goal through a unique set of interrelated effective use of resources, tasks and can be project resources in this context in the form of financial support and the resources of a human, machines, and computer programs.

$\underline{2^{\mathrm{ND}} \text { project management professional }}$

(Kerzner, 2003: 3) defines project management as: planning, organizing, directing and controlling resources companies to achieve a short-term goal of a relatively created to accomplish specific goals while the project management according to (OGC, 2009: 17) is planning, delegating, monitoring and control on all aspects of the project to achieve the objectives of the project within the expected time, cost, quality, scope, benefits and risks of performance goalsThe definition of (PMBOK, 2017: 10) for project management in conformity with the versions (PMBOK previously), as defined as the 
application of knowledge, skills, tools and techniques to project activities to meet project requirements and through the application and integration of appropriate processes specific project management Moreover, it has stated (Kerzner \& Saladis, 2019: 30) The professional management projects contribute to the identification of roles and responsibilities, setting priorities, deadlines and prepare realistic schedules time management.

\section{$\underline{3}^{\text {rd }}$ PMBOK Methodology:}

the guide Knowledge Project Management (PMBOK) as the term is abbreviated for (Project Management Body Of Knowledge) and meaning (the structure of the knowledge management projects) description (Sonnekus \& Labuschagne, 2006: 184) PMBOK® it is a set of ethics and standards developed by the project management institute PMI the project management functions if the IS PMBOK the inclusive term, describes the sum of knowledge in the project management profession. (Arends, 2013:32) mentioned that there are ten knowledge areas divided into two main categories: core functions (scope, time, cost and quality) and facilitating functions (human resources, communications and procurement, stakeholders) with the management of the integration that connects them all to each other while (Marshuka, 2014: 27) mentioned the PMBOK is the project management methodology traditional the most widely used and has gained universal acceptance when it was released in 1996 free on the website.

\section{PRACTICAL SIDE / RESULTS OF THE PRACTICAL ANALYSIS}

The researcher was based on three statistical measures represented by the calculations weighted, and applied these standards on each groups of project management tasks requirements which including (Initiation, planning, implementation, monitoring and control, closing), according to the assessment manual (Project Management Experience and Knowledge Self-Assessment) issued by the Institute of project Management professional projects and can find it on the link (https://bok.cc/book/956025/fc1a72).

\section{First: Assessment the results of Task Statement for project management}

1- Task Statements For Initiation group: Is evaluated criterion of Task Statement For Initiation (10 items, each paragraph is assessed through three levels ( high, medium, low ), as of weights respectively 2.4 / 1.2 / 0.4 as is evaluated trend level as table (1):

Table (1) Task Statement for Initiation Group

\begin{tabular}{|c|c|c|c|c|}
\hline \multirow[b]{2}{*}{$\dot{\mathscr{D}}$} & \multirow[b]{2}{*}{ Task Statements For Initiation The Project } & \multicolumn{3}{|c|}{ BaghdadGovernorate } \\
\hline & & 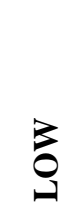 & $\underset{\sum}{\stackrel{\Xi}{g}}$ & 氠 \\
\hline 1 & $\begin{array}{l}\text { Define project objectives by identifying the stakeholders in the project and } \\
\text { work with them in order to meet their requirements and their specifications } \\
\text { and / or expectations. }\end{array}$ & & & \# \\
\hline
\end{tabular}




\begin{tabular}{|c|c|c|c|c|}
\hline 2 & $\begin{array}{l}\text { Identify outputs or outputs of the product or service by reviewing or } \\
\text { establishing requirements and / or specifications to meet the expectations of } \\
\text { stakeholders. }\end{array}$ & & & \# \\
\hline 3 & $\begin{array}{l}\text { Determine the project management process outputs through the application } \\
\text { of practices and appropriate tools and methodologies to ensure product / } \\
\text { service required }\end{array}$ & \# & & \\
\hline 4 & $\begin{array}{l}\text { Documentation of project restrictions through coordination with } \\
\text { stakeholders and reviewing policies and procedures to ensure compliance. }\end{array}$ & $\#$ & & \\
\hline 5 & $\begin{array}{l}\text { Documenting assumptions by identifying information that must be validated } \\
\text { or situations where the project should be controlled during the process in } \\
\text { order to facilitate the project planning process. }\end{array}$ & $\#$ & & \\
\hline 6 & $\begin{array}{l}\text { The project strategy definition through the evaluation of alternative } \\
\text { approaches to meet stakeholders, requirements and specifications, and / or } \\
\text { expectations. }\end{array}$ & \# & & \\
\hline 7 & $\begin{array}{l}\text { Define performance criteria by reference to the product / service } \\
\text { specifications and standards process in order to ensure and / or support the } \\
\text { quality assurance efforts. }\end{array}$ & $\#$ & & \\
\hline 8 & $\begin{array}{l}\text { Identify key resource requirements by reference to the target outputs for } \\
\text { planning and decision-making support. }\end{array}$ & $\#$ & & \\
\hline 9 & $\begin{array}{l}\text { Determine the appropriate time budget for the project schedule by setting } \\
\text { the time and cost estimates to support decision-making }\end{array}$ & & & \# \\
\hline 10 & $\begin{array}{l}\text { Provide comprehensive information by issuing official documents to obtain } \\
\text { the approval of the decision of the stakeholders }\end{array}$ & & \# & \\
\hline \multicolumn{2}{|c|}{ ) Total for each Column( } & 6 & 1 & 3 \\
\hline \multicolumn{2}{|c|}{ 0.4Score for Low Col.= Col. Total $*$} & \multicolumn{3}{|l|}{2.40} \\
\hline \multicolumn{2}{|c|}{ Score for Medium Col.=Col. Total $* \mathbf{0 . 8}$} & \multicolumn{3}{|l|}{$\mathbf{0 . 8 0}$} \\
\hline \multicolumn{2}{|c|}{ Score for High Col.=Col. Total $* 1.2$} & \multicolumn{3}{|l|}{3.6} \\
\hline \multicolumn{2}{|c|}{ Total Score For Initiation Group } & \multicolumn{3}{|l|}{6.80} \\
\hline \multicolumn{2}{|c|}{ Average } & \multicolumn{3}{|l|}{0.68} \\
\hline
\end{tabular}




\begin{tabular}{|l|l|}
\hline Percentage of matching & $\mathbf{5 7 \%}$ \\
\hline Gap & $\mathbf{4 3 \%}$ \\
\hline
\end{tabular}

From the results of Table (1) shows that the Baghdad governorate got rate is (0.68) value (Medium), also note that percentage of the matching was (57\%), while gap was (43\%), And return the results to the presence of deficiencies in the performance of the Initiation tasks and varying proportions as back causes to the absence of knowledge or failure: First to adopt a clear methodology for the management of the project and secondly identify stakeholders and how their management and thirdly develop assumptions that are considered a source of risk and how to control the duration of the project.

2-Task Statements For Planning group: Is evaluated criterion of Task Statement For Planning of (7 items, each paragraph is assessed through three levels ( high, medium, low ), as of weights respectively $6.27 / 4.18 / 2.09$ as is evaluated trend level as table (2):.

Table (2) Task Statements For Planning group

\begin{tabular}{|c|c|c|c|c|}
\hline \multirow[b]{2}{*}{ ळ் } & \multirow{2}{*}{ Task Statements For Planning The Project } & \multicolumn{3}{|c|}{$\begin{array}{l}\text { Baghdad } \\
\text { Governorate }\end{array}$} \\
\hline & & 3 & 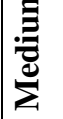 & 武 \\
\hline 1 & $\begin{array}{l}\text { Improve project requirements, assumptions, and limitations through } \\
\text { communication with stakeholders and / or through a review of project } \\
\text { documents to determine the scope of work and enable the development of the } \\
\text { implementation plan. }\end{array}$ & \# & & \\
\hline 2 & $\begin{array}{l}\text { Create (WBS) work breakdown Structure By using Scope of work and Others } \\
\text { Projects Documentsand techniques to facilitate the decomposition of detailed } \\
\text { project implementation processes, monitoring and closure planning. }\end{array}$ & \# & & \\
\hline 3 & $\begin{array}{l}\text { Develop a plan for the management of resources (human resources, } \\
\text { procurement, etc.) by identifying resource requirements and to obtain } \\
\text { commitments from internal and external sources and procurement for the } \\
\text { completion of all project activities. }\end{array}$ & \# & & \\
\hline 4 & $\begin{array}{l}\text { Improve project time and cost estimates through the application of tools / } \\
\text { techniques for the estimation of all WBS to identify and define the baseline for } \\
\text { the project schedule and budget functions. }\end{array}$ & \# & & \\
\hline
\end{tabular}




\begin{tabular}{|c|c|c|c|c|}
\hline 5 & $\begin{array}{l}\text { Establish project control, communication, procurement, risk, quality and } \\
\text { human resources to facilitate project implementation by identifying the } \\
\text { processes, measures and appropriate controls required for project change } \\
\text { management Control and ensure compliance with recognized standards of } \\
\text { work. }\end{array}$ & \# & & \\
\hline 6 & $\begin{array}{l}\text { A formal and comprehensive project plan that accepts standards, processes, } \\
\text { procedures and tasks through integration and recording of output to facilitate } \\
\text { project implementation, control and closure. }\end{array}$ & & \# & \\
\hline 7 & $\begin{array}{l}\text { Obtaining the approval of the project plan by reviewing the plan with the client } \\
\text { and other stakeholders wanted to confirm the project baselines before } \\
\text { embarking on the implementation of the operations of the project. }\end{array}$ & & & \# \\
\hline \multicolumn{2}{|c|}{ Total for each Column( } & 5 & 1 & 1 \\
\hline \multicolumn{2}{|c|}{ 2.09Score for Low Col.= Col. Total $*$} & \multicolumn{3}{|l|}{10.45} \\
\hline \multicolumn{2}{|c|}{ Score for Medium Col.=Col. Total $* 4.18$} & \multicolumn{3}{|l|}{4.18} \\
\hline \multicolumn{2}{|c|}{ Score for High Col.=Col. Total $* 6.27$} & \multicolumn{3}{|l|}{6.27} \\
\hline \multicolumn{2}{|c|}{ Total Score For Planning Group } & \multicolumn{3}{|l|}{20.90} \\
\hline \multicolumn{2}{|c|}{ Average } & \multicolumn{3}{|l|}{2.99} \\
\hline \multicolumn{2}{|c|}{ Percentage of matching } & \multicolumn{3}{|l|}{$48 \%$} \\
\hline \multicolumn{2}{|c|}{ Gap } & \multicolumn{3}{|l|}{$52 \%$} \\
\hline
\end{tabular}

From the results of Table (2) shows that the Baghdad governorate got rate is (2.99) value (low), also note that percentage of the matching was (48\%), while gap was (52\%), A weakness in the application of the planning process tasks statement in varying proportions and close as back causes to failure: First definition and stakeholder participation in the planning process and secondly the preparation of work fragmentation of structures and the use of technology in the process of analysis and preparation of work schedules as well as the application of tools and techniques for improving time and cost the quality of the project and thirdly the development of the various assessments of resources and in line with the business requirements of the project and fourth coordination with internal and external parties to the project by opening channels of communication.

3- Task Statements For Executing group: Is evaluated criterion of Task Statement For Executing of (5 items, each paragraph is assessed through three levels ( high, medium, low ), as of weights respectively 17.2 / 11.4 / 5.7 as is evaluated trend level as table (3):. 
Table (3) Task Statements For Executing group

\begin{tabular}{|c|c|c|c|c|}
\hline \multirow[b]{2}{*}{$\dot{\check{D}}$} & \multirow{2}{*}{ Task Statements For Executing The Project } & \multicolumn{3}{|c|}{$\begin{array}{l}\text { Baghdad } \\
\text { Governorate }\end{array}$} \\
\hline & & $\stackrel{3}{3}$ & : & 象 \\
\hline 1 & $\begin{array}{l}\text { Commitment to the project resources in accordance with the project plan to } \\
\text { ensure the implementation of all activities }\end{array}$ & & \# & \\
\hline 2 & $\begin{array}{l}\text { Implementation of the project plan through the permit or authorization to } \\
\text { implement the project activities and tasks to be performed for the production of } \\
\text { project outputs }\end{array}$ & & \# & \\
\hline 3 & $\begin{array}{l}\text { Manage project schedule progress to ensure that project objectives are carried } \\
\text { out as planned }\end{array}$ & \# & & \\
\hline 4 & $\begin{array}{l}\text { Reporting on the progress made in the project through the production of project } \\
\text { reports to provide project status in a timely and accurate information and } \\
\text { support for the objectives of the project stakeholders }\end{array}$ & \# & & \\
\hline 5 & $\begin{array}{l}\text { Implementation of quality assurance procedures by conducting project } \\
\text { monitoring activities to achieve the objectives of the project }\end{array}$ & \# & & \\
\hline \multicolumn{2}{|c|}{ (Total for each Column) } & 3 & 2 & 0 \\
\hline \multicolumn{2}{|c|}{ 5.7Score for Low Col.= Col. Total $*$} & \multicolumn{3}{|c|}{17.1} \\
\hline \multicolumn{2}{|c|}{ Score for Medium Col.=Col. Total $* 11.4$} & \multicolumn{3}{|c|}{22.8} \\
\hline \multicolumn{2}{|c|}{ Score for High Col.=Col. Total $* 17.2$} & \multicolumn{3}{|c|}{00.00} \\
\hline \multicolumn{2}{|c|}{ Total Score For Executing Group } & \multicolumn{3}{|c|}{39.90} \\
\hline \multicolumn{2}{|c|}{ Average } & \multicolumn{3}{|c|}{7.98} \\
\hline \multicolumn{2}{|c|}{ Percentage of matching } & \multicolumn{3}{|c|}{$46 \%$} \\
\hline \multicolumn{2}{|c|}{ Gap } & \multicolumn{3}{|c|}{$54 \%$} \\
\hline
\end{tabular}


From the results of Table (3) shows that the Baghdad governorate got rate is (7.98) value (low), also note that percentage of the matching was (46\%), while gap was $(54 \%)$, The results refer to a lack of deficiencies in the requirements management is important in this area which back causes to vulnerabilities in: The first administration of the various resources in the project and use the matrix to assign responsibilities and document the roles and responsibilities of individuals or groups for various elements of the project and then document relationships reports to each of them to ensure the implementation of all the activities in the progress of the work schedule and secondly I said, the skill of project managers and thirdly the preparation of reports scheduled daily and weekly reviews and monthly reports of performance to stand on the status of the project throughout the implementation period, and fourth the procedures of Quality Assurance (Quality Assurance ) not set ((Quality Control through participation opportunities, auditing and detection of the defects by the kids of the interior and the implementation of corrective action (Correction Orders ) or actions to prevent defects (prevention Orders).

4- Task Statement For Monitoring \& Controlling: Is evaluated criterion of Task Statement For control and Monitoring of ( 8 items, each paragraph is assessed through three levels ( high, medium, low ), as of weights respectively 5.7 / 3.8 / 1.9 as is evaluated trend level as table (4):.

Table (4) Task Statements for controlling group

\begin{tabular}{|c|c|c|c|c|}
\hline \multirow[b]{2}{*}{$\dot{\dot{\nu}}$} & \multirow{2}{*}{$\begin{array}{l}\text { Task Statements For Controlling \& Monitoring The } \\
\text { Project }\end{array}$} & \multicolumn{3}{|c|}{$\begin{array}{l}\text { Baghdad } \\
\text { Governorate }\end{array}$} \\
\hline & & $\stackrel{3}{3}$ & 莺 & 胥 \\
\hline 1 & $\begin{array}{l}\text { Measure the performance of the project continuously by comparing the results to } \\
\text { the baseline to determine trends and differences in the project. }\end{array}$ & \# & & \\
\hline 2 & $\begin{array}{l}\text { Improve the limits or control restrictions on performance measures through the } \\
\text { application or set policy in place in order to determine the needs of corrective } \\
\text { actions }\end{array}$ & \# & & \\
\hline 3 & $\begin{array}{l}\text { Take corrective action in a timely manner by addressing the root causes of the } \\
\text { problem areas in order to eliminate the negative effects or minimize them }\end{array}$ & & \# & \\
\hline 4 & $\begin{array}{l}\text { Evaluate the effectiveness of corrective actions through subsequent performance } \\
\text { measurement in order to determine the need for further action }\end{array}$ & \# & & \\
\hline 5 & $\begin{array}{l}\text { Ensure compliance with the management plan change by monitoring the response } \\
\text { to change initiatives in order to manage scale }\end{array}$ & \# & & \\
\hline 6 & $\begin{array}{l}\text { Re-evaluation of control project plans by scheduling periodic audits to ensure } \\
\text { their effectiveness and suitability }\end{array}$ & \# & & \\
\hline
\end{tabular}




\begin{tabular}{|c|c|c|c|c|}
\hline 7 & $\begin{array}{l}\text { Respond to the players or the requirements of dangerous events, according to the } \\
\text { risk management plan in order to manage the project results properly }\end{array}$ & $\#$ & & \\
\hline 8 & $\begin{array}{l}\text { Promote advocacy for prevention by organizing preventive awareness campaigns } \\
\text { to promote public policies and regulations }\end{array}$ & \# & & \\
\hline \multicolumn{2}{|c|}{ (Total for each Column) } & 7 & 1 & $\mathbf{0}$ \\
\hline \multicolumn{2}{|c|}{ 1.9Score for Low Col.= Col. Total * } & \multicolumn{3}{|l|}{13.30} \\
\hline \multicolumn{2}{|c|}{ Score for Medium Col.=Col. Total $* \mathbf{3 . 8}$} & \multicolumn{3}{|l|}{3.80} \\
\hline \multicolumn{2}{|c|}{ Score for High Col.=Col. Total $* 5.7$} & \multicolumn{3}{|l|}{0.00} \\
\hline \multicolumn{2}{|c|}{ Total Score For Controlling Group } & \multicolumn{3}{|l|}{17.10} \\
\hline \multicolumn{2}{|c|}{ Average } & \multicolumn{3}{|l|}{2.14} \\
\hline \multicolumn{2}{|c|}{ Percentage of matching } & \multicolumn{3}{|l|}{$38 \%$} \\
\hline \multicolumn{2}{|c|}{ Gap } & \multicolumn{3}{|l|}{$62 \%$} \\
\hline
\end{tabular}

From the results of Table (4) shows that the Baghdad governorate got rate is (2.14) value (low), also note that percentage of the matching was (38\%), while gap was $(62 \%)$, The results indicate that there are deficiencies in the performance of tasks data in this area, which causes dating back to the presence of weak knowledge in: First, take corrective measures and measures to prevent defects and evaluated after implementation procedures, and secondly the issuance of documents examination for measuring, testing and testing and confirmation of conformity with the specifications as well as a plan of action for any activity before direct implementation as the basic philosophy of quality management project adopted by the PMI is the process of being carried out to ensure that the project will meet all the required characteristics, and thirdly to measure the performance of the project through the use of cost control, scheduling and quality of the project and techniques IV brain control Frameworks and develop appropriate strategies to respond in a timely manner.

5- (Task Statement for Closing Group): is evaluated of the criterion closing group (Task Statement For Closing) from (5) paragraph as assessed per paragraph through three levels (high, medium, low) as of weights respectively (2.4, $1.6,0.8)$, as is evaluated trend level as table (5): 
Table (5) Task Statements For Closing group

\begin{tabular}{|c|c|c|c|c|}
\hline \multirow[b]{2}{*}{$\dot{\check{D}}$} & \multirow{2}{*}{ Task Statements For Closing The Project } & \multicolumn{3}{|c|}{$\begin{array}{l}\text { Baghdad } \\
\text { Governorate }\end{array}$} \\
\hline & & $\overbrace{}^{2}$ & $\stackrel{\Xi}{\Xi}$ & 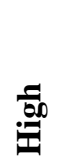 \\
\hline 1 & $\begin{array}{l}\text { Obtaining final acceptance of achievements by obtaining formal approval from } \\
\text { the appropriate stakeholders to achieve closure }\end{array}$ & & & $\#$ \\
\hline 2 & $\begin{array}{l}\text { Documenting lessons learned through the survey project members and other } \\
\text { stakeholders team to take advantage of them in future projects }\end{array}$ & \# & & \\
\hline 3 & $\begin{array}{l}\text { Facilitate the administrative and financial closure in accordance with the project } \\
\text { plan in order to comply with the requirements of the institution and stakeholders }\end{array}$ & & \# & \\
\hline 4 & $\begin{array}{l}\text { Keeping main records of the project and the tools required by archiving for use } \\
\text { in the future to comply with legal requirements and other }\end{array}$ & \# & & \\
\hline 5 & $\begin{array}{l}\text { Release project resources through appropriate regulatory procedures for optimal } \\
\text { use of resources. }\end{array}$ & \# & & \\
\hline \multicolumn{2}{|c|}{ (Total for each Column) } & 3 & 1 & 1 \\
\hline \multicolumn{2}{|c|}{ 0.8Score for Low Col.= Col. Total * } & \multicolumn{3}{|l|}{2.40} \\
\hline \multicolumn{2}{|c|}{ Score for Medium Col.=Col. Total $* 1.6$} & \multicolumn{3}{|l|}{1.60} \\
\hline \multicolumn{2}{|c|}{ Score for High Col.=Col. Total $* 2.4$} & \multicolumn{3}{|l|}{2.4} \\
\hline \multicolumn{2}{|c|}{ Total Score For Closing Group } & \multicolumn{3}{|l|}{6.40} \\
\hline \multicolumn{2}{|c|}{ Average } & \multicolumn{3}{|l|}{1.28} \\
\hline \multicolumn{2}{|c|}{ Percentage of matching } & \multicolumn{3}{|l|}{$53 \%$} \\
\hline \multicolumn{2}{|c|}{ Gap } & \multicolumn{3}{|c|}{$47 \%$} \\
\hline
\end{tabular}

From the results of Table (5) shows that the Baghdad governorate got rate is (1.28) value (low), also note that percentage of the matching was (53\%), while gap was (47\%), and analysis of the above results indicate that there are weaknesses in the application areas of performance tasks The process of closure, which date back causes to: first, lack of lessons learned that can prepare a cognitive and educational approach that can be consulted in subsequent projects to 
reduce non-cases confirmed, time and cost and is thus one of the important organizational assets, and secondly to use the style of disintegration or (resolution team) Documentation (Adjourning ) after arriving successfully to the targets set and the end of work and the appropriate regulatory measures followers with the need to evaluate the work of all members for the purpose of benefiting from their experience in similar projects in the future.

\section{Second: Final Assessment of Project Management Task Statement Requirements:}

Reference to the results above are assessed the total requirements for task statement for project management according to the checklist issued by the Institute of Professional Project Management where the highest score for the evaluation of Task statement requirements for project management is $(199,69)$ as the evaluation categories are (below average, within Rate, above average (where the total, which represents the total points for all project operations (start, planning, implementation, monitoring and control, closure) with comparative scores for the Task statement requirements of project management where the results are as shown in Table (6):

Table (6) Final Assessment for Task statement of Project Management

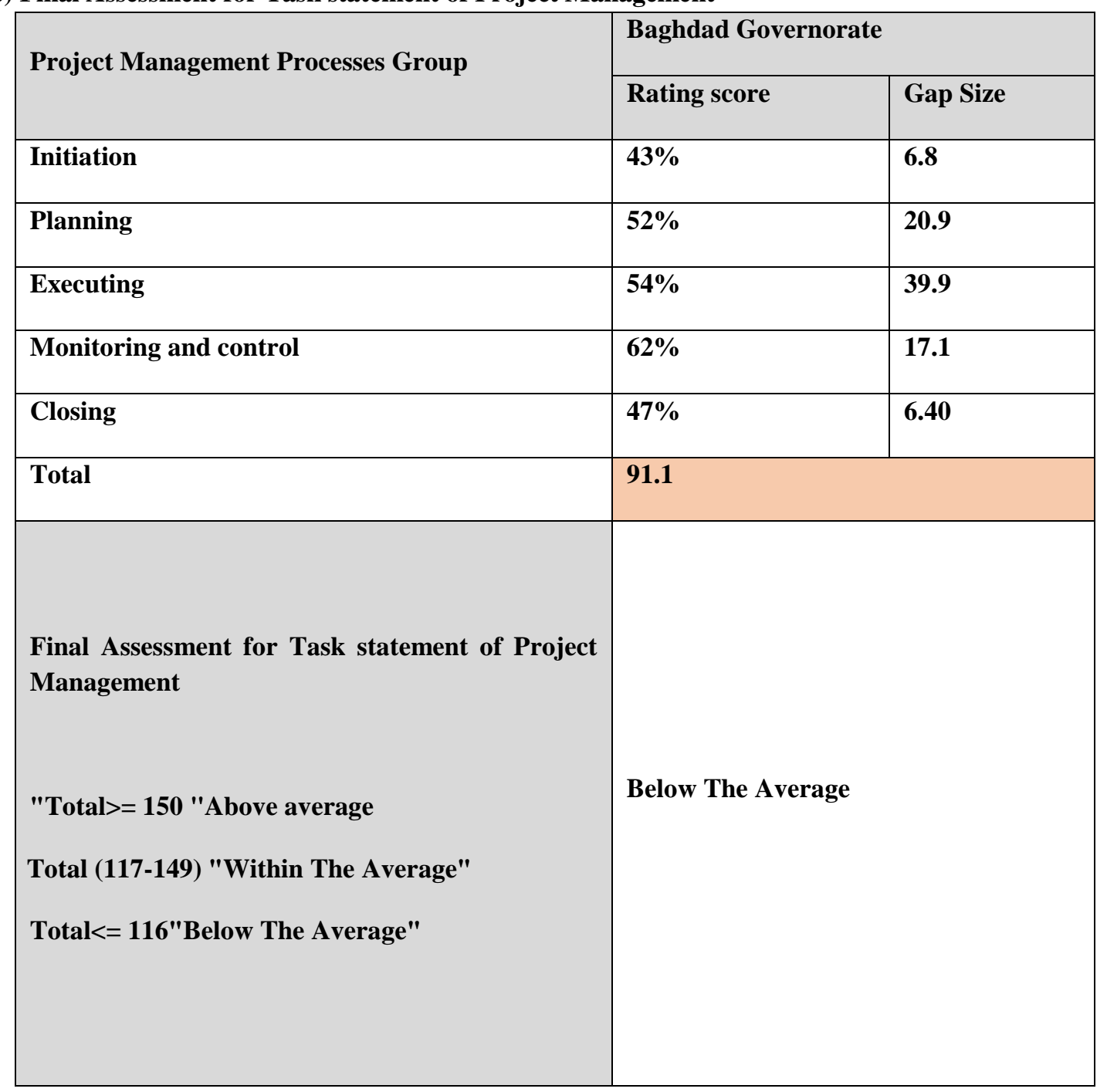

According to table (6), the total score for the Baghdad Governorate (91.1), which is considered below the assessment rate While the highest gap was recorded for the control and control Processes group (62\%). 


\section{CONCLUSION AND RECOMMENDATIONS}

\section{First: Conclusions}

The results of this work have shown that there is a gap in the areas of performance management projects in the sectors of service organizations surveyed, and this is mainly due to the lack of a formal adoption of the methodology of the project with clear mechanisms for the implementation of the project was clear from the results that the project management did not follow an integrated system.

\section{Second: Recommendations}

The need to achieve the project management culture by raising awareness and holding training courses and attend work or classes or conferences workshops on the management of the project to build a formal public awareness as it is possible to use the pre-qualification and subsequent evaluation of the service providers as a tool to improve the areas of performance for all groups of project management processes.

As well as, it is necessary to adopt project management effectively in its activities through the establishment of offices of project management in order to provide support and guidance for their projects.

\section{REFERENCE:}

1- Arendse, J.R., 2013. Project management competency factors in the built environment (Doctoral dissertation, University of Johannesburg).

2- Burke, R., 2009. Project management: planning and control techniques, New Jersey, USA, 26.

3- Clements, J.P. and Gido, J., 2006. Effective project management. Evans Publishing Group.

4- Kerzner, H. and Saladis, F.P., 2017. Project management workbook and PMP/CAPM exam study guide. John Wiley \& Sons.

5- Kerzner, H.,2003, Project Management: A Systems Approach to Planning, Scheduling, and Controlling. (8th Edition) New Jersey: John Wiley and Sons.

6- Marchewka, J. 2014. Information technology project management: providing measurable organisational value. New York: Wiley.
7- Maylor, H. ,2010,Project Management, Pearson. British Library Cataloguing-inPublication Data.

8- Nwagbogwu, D.C., 2011. The correlation between project management effectiveness and project success. Walden University.

9- PMBoK, A., 2017. A guide to the project management body of knowledge (PMBOK guide). Project Management Institute, Inc..

10- Project Management Institute ,2000, Project Management Experience and Knowledge Self-assessment (https://bok.cc/book/956025/fc1a72).

11- S CHOUDHURY,2009PROJECT MANAGEMENT, published by McGraw Hill India.

12- Söderlund, J., 2004. Building theories of project management: past research, questions for the future. International journal of project management, 22(3), pp.183-191.

13- Sonnekus, R. and Labuschagne, L., 2006. Establishing the relationship between IT project management maturity and IT project success in a South African context.

14- Turner, J.R., 2009. The handbook of projectbased management. London: McGraw-Hill.

15- UK Office of Government Commerce (OGC),2006, Prince2: a practical handbook.

16- van Aarssen, K.L., 2010. Trust within temporary organizations: The influence of prior ties. 